\title{
Substantiation of the parameters of the tailings storage core during the storing of the cleaning rejects by hydraulic method
}

\author{
Olha Medvedieva ${ }^{1, *}$, Serhii Kyrychko ${ }^{1}$, Nina Nykyforova $^{2}$, and Nataliia Koval $^{1}$ \\ ${ }^{1}$ Institute of Geotechnical Mechanics named by N. Poljakov of National Academy of Sciences of \\ Ukraine, 49005, Dnipro, Simferopolska Str., 2a, Ukraine \\ ${ }^{2}$ National Metallurgical Academy of Ukraine, 49000, Dnipro, Haharina Ave., 4, Ukraine
}

\begin{abstract}
The paper analyzes the current state of artificial tailings storages. These unique anthropogenic facilities may be considered both as the sources of environmental hazard and as promising anthropogenic deposits. The relevance of their development is shown. Taking into account the existing technologies of tailings storing, it is substantiated that the future anthropogenic deposit is formed by hydraulicking layers of the same thickness, displaced relative to each other in the horizontal plane by the same amount. As a result of research dependences were obtained that allow estimation of the probable volumes of stored mineral processing products and available storage volume when building up dams, as well as justification of the location of the inner boundary between the core of the artificial storage and the body of the retaining prism.
\end{abstract}

\section{Introduction}

There are about 25 billion tons of solid waste products accumulated in Ukraine. These waste products occupy about 150 thousand hectares of fertile land and have a negative influence on natural landscape and environmental conditions [1 - 3]. Occupied areas are taken out of economic activity, but neighbouring lands become degraded because of dust pollution from waste piles and tailings storages. Known technologies of dams building up for tailings storages don't ensure their effective operation now, but only deepen environmental hazard of industry. So the main problems and the tasks for domestic oredressing and processing enterprises are resource-saving technologies, decrease in the energy intensity of transportation and storing of mineral processing products, lowering of anthropogenic influence on environment, increase in environmental safety.

\section{Methods}

Tailings storages (TS) of Kryvyi Rih basin ore-dressing and processing enterprises are huge reservoirs walled in dumps consisting of sludge and barren rock and impounded with pulp

\footnotetext{
*Corresponding author: medvedevaolga1702@gmail.com
} 
(mixture of disintegrated cleaning rejects with water). These unique anthropogenic facilities may be considered both as the sources of environmental hazard and as promising anthropogenic deposits [ $1-4]$. These TS are characterized by long operation life. Placing of mineral processing products occurs by layers one over another with becoming buildingup of retaining dams. Stored iron ore cleaning rejects predominately consist of quartz; lowgrade quartz aggregates with hematite; magnetite. The prevalent chemical elements are silicon (about $58.61 \%$ in terms of silicon dioxide) and iron (under $12.14 \%$ ). This is specified by the iron-ore concentration technology established in Kryvyi Rih basin. It is based on three or four stages of magnetic separation when only magnetite is recovered into commodity concentrate, but hematite is discharged into cleaning rejects as a weak-magnetic mineral. Bulk of solid phase of cleaning rejects containing ferruginous quartzite falls out on the dusting surface of the hydraulicking layer and doesn't get to the storage core. According to research $[4,5]$ there may be transition zone, containing valuable components, between the core and the dusting surface sometimes. But conditions of this zone formation are not studied and its boundaries are not determined. This hampers estimation of boundaries of anthropogenic placers and restrains elaboration of technological solutions for their development. So elaboration of technologies of development of anthropogenic placers at Kryvyi Rih basin ore-dressing and processing enterprises requires substantiation of inner boundary between TS core and retaining prism formed during the storing of mineral processing products. It is an actual problem at present.

Known calculation procedures allow determination of retaining prism volume, volume of stored cleaning rejects and available storage volume counting off from retaining prism height [1]. But they don't allow establishment of location of inner boundary between TS core and retaining prism body (Fig. 1).

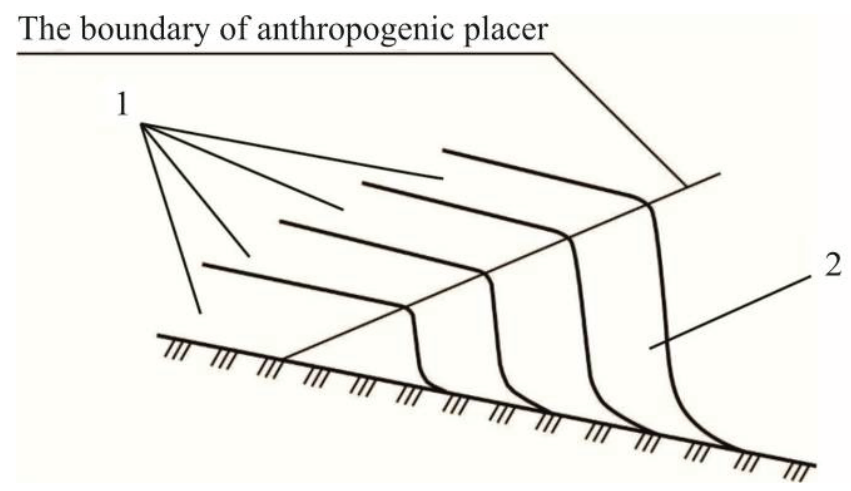

Fig. 1. Location of inner boundary between TS core and retaining prism body: 1 - layers of consecutive hydraulicking; 2 - zone of underwater hydraulicking.

Stored volume of solid particles is an actual potential of future anthropogenic deposit. Taking into account the existing technology for the tailings storing, it is substantiated that the future anthropogenic deposit is formed by hydraulicking layers of the same thickness, displaced relative to each other in the horizontal plane by the same amount (Fig. 2).

It should be noted that the length of the underwater surface is reducing with each new layer. It means that the part of solid particles placed by underwater hydraulicking falls out in quite other conditions if the boundary of underwater surface of previous layer is reached [5 - 9]. Actually this part of solid particles will fall out in the pond zone forming certain body beyond the bounds of hydraulicking body of the previous layer as its extension. Then the particles of the current hydraulicking layer will place on this body in calculated conditions. 


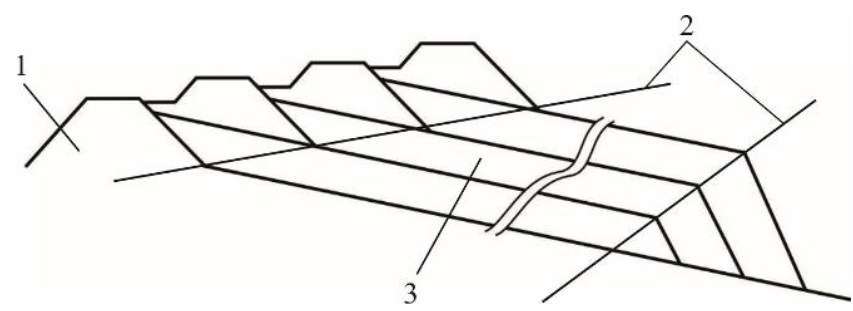

Fig. 2. The scheme of anthropogenic deposit forming: 1 - retaining dam; 2 - the boundary of anthropogenic placer; 3 - layers of consecutive hydraulicking.

It would seem that the bed of the future anthropogenic placer should shift by $\Delta$ when moving to the new hydraulicking layer (Fig. 3). But the remote part of the underwater surface with length $\Delta$ has nothing to lean on because of the absence of placer previous layer under it. So three variants of valuable component particles placing process may be marked out (Fig. 3, Table 1).

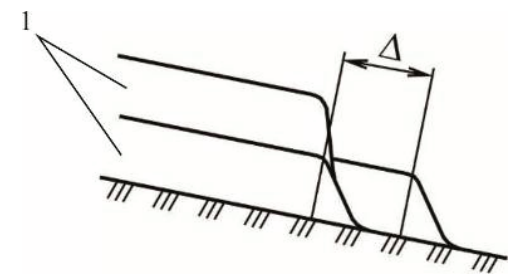

a)

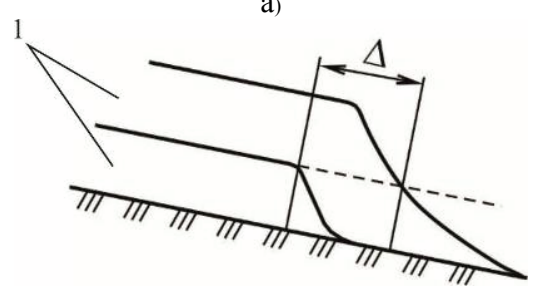

b)

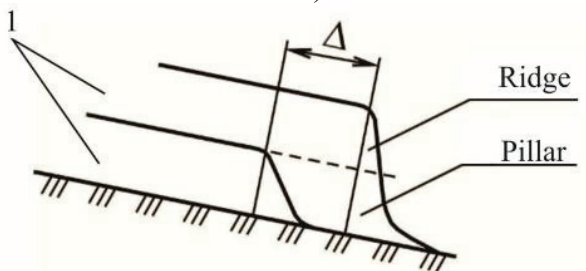

c)

Fig. 3. Possible variants of formation of boundary layer between the core and the retaining prism: a) Variant I; b) - Variant II; c) - Variant III; 1 - layers of consecutive hydraulicking.

Table 1. Description of possible variants of forming of boundary layer between the core and the retaining prism.

\begin{tabular}{|c|l|}
\hline Variant & \multicolumn{1}{|c|}{ Process features } \\
\hline I & This piece «fell» from higher hydraulicking layer \\
\hline II & $\begin{array}{l}\text { Particles from higher layer form new slope taking into account new } \\
\text { sedimentation conditions. }\end{array}$ \\
\hline III & $\begin{array}{l}\text { Particles form pillar at first and then following particles of this layer form } \\
\text { "piece". It is necessary to discharge more material for this variant of } \\
\text { formation. }\end{array}$ \\
\hline
\end{tabular}


Variant I (Fig. 3.a, Table 1) gives the simplified process representation. In this case we assume that all particles, which were ought to extend the current hydraulicking layer to given length, in fact extend the previous hydraulicking layer to the same length. In this case some part of the current hydraulicking layer "falls" from the forming layer on the previous one. According to variant II (Fig. 3.b, Table 1) the particles, which form interface during sedimentation process, have to get over two times greater depth than particles, which form the current layer surface. Therefore the slope is forming for two layers at once and has other inclination. In the case of variant III (Fig. 3.c, Table 1) we assume that each following layer encloses more particles than previous one because it forms ever greater "pillar" every time. In addition the fine particles from the pond are admixing to the base of such "pillar" and contaminate future anthropogenic placer.

Models of processes of formation of intermediate zone between the retaining prism body and the TS core are unknown and calculation methods for parameters of this zone are absent also. Some researchers mention three different forms of prism body, which may be matched with formulated variants of formation process (Table 2) [1, 4, 5, 8 - 11]. The forms of retaining prism body differ from each other by inner slope inclination:

- in some cases angle is acute, as well as in the retaining dams;

- this angle may be close to the right angle;

- retaining prisms with a blunt angle of the inner slope are known also.

Acute angle of the inner slope of the retaining prism is forming when variant I of intermediate zone formation is realized at the expense of sliding of end parts of higher hydraulicking layers on the previous ones. The angle of the inner slope of the retaining prism is close to the right angle when variant II of intermediate zone formation is realized. In this case the slopes displace the ridge and interface to a small extent because they are washed out during underwater placing. Blunt angle of the inner slope comes out of variant III realization when hydraulicking of the current layer is accomplished on the "pillar". This results in interface moving deep into the TS core [1, 4, 5, 8-10, 12].

At the same time high accuracy in determination of boundary of intermediate zone between the retaining prism and the TS core is not required in terms of the formation of anthropogenic deposit. The valuable component is concentrated near the dam on the dusting surface and it is not planned to mine it in the zone of underwater hydraulicking. So it is important to estimate some boundary of transition zone. Content of the valuable component or its contamination by slimes beyond the bounds of this zone will be unacceptable in terms of reprocessing. Therefore the boundary between the transition zone and the dusting surface will be considered for determination of mining parameters during anthropogenic deposit development. This boundary is characterized by the distance between the inner border of the retaining dam and anthropogenic placer boundary, or intermediate zone beginning on the higher surface of current hydraulicking layer (Fig. 4). It may be also characterized by the distance between the inner border of the retaining dam and intermediate zone beginning measured horizontally.

Thereby the anthropogenic placer is that part of stored cleaning rejects, which precipitates from the flow and doesn't get to the pond. It is evident that the most valuable part of cleaning rejects is storing on the dusting surface, but the part, formed by underwater hydraulicking, is less valuable (Fig. 5). It is necessary to know dependences of hydraulicking layer length, dusting surface length and underwater hydraulicking length on number of hydraulicking layer for determination of mining parameters. It requires solving of tasks of fractionation of particles on the dusting surface and of underwater hydraulicking of particles remained after the dusting surface formation for conditions of each hydraulicking layer (Fig. 6).

Solutions of these tasks will allow determination of $\Delta$ for each layer. If dependence of $\Delta$ on number of hydraulicking layer as well as parameters of retaining dams and retaining 
prism are known (Fig. 6) it is possible to define desired function as

$$
\begin{array}{r}
\Delta=p h(\eta(1+e)+\operatorname{ctg} \alpha), \\
\eta=\frac{E}{h}, \quad e=\frac{b}{E},
\end{array}
$$

where $\Delta$ - displacement of anthropogenic placer bed on each hydraulicking layer, $\mathrm{m} ; p-$ coefficient of change of total length of the dusting surface, which depends on variant of transition zone formation (Table 3); $E$ - width of retaining dam top, m; $\alpha$ - slope angle of retaining dam; $h$ - thickness of hydraulicking layer, $\mathrm{m} ; b$ - width of retaining dam berm, $\mathrm{m}$.

Table 2. Correspondence between retaining prism types and variants of transition zone formation.

Variant




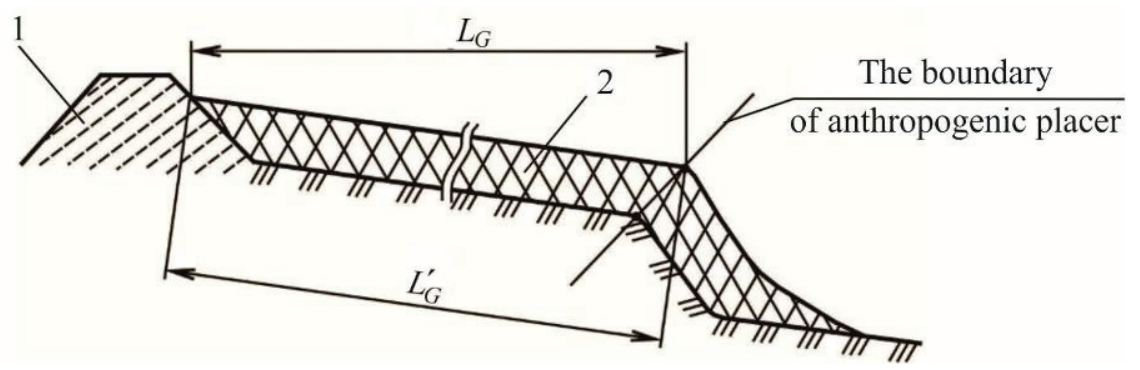

Fig. 4. Determination of the boundary of anthropogenic placer: 1 - retaining prism; 2 - anthropogenic placer.

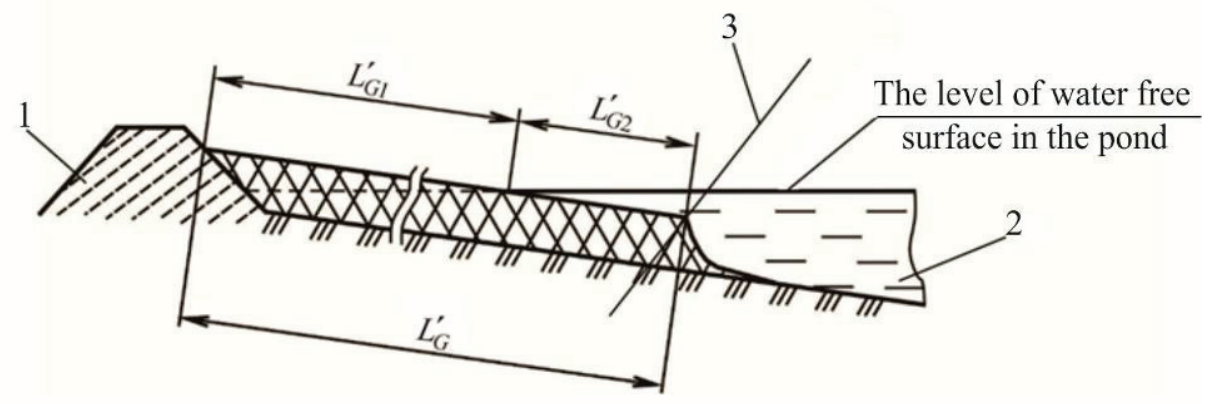

Fig. 5. Boundaries of anthropogenic placer zones: 1 - retaining dam; 2 - pond; 3 - the boundary of anthropogenic placer.

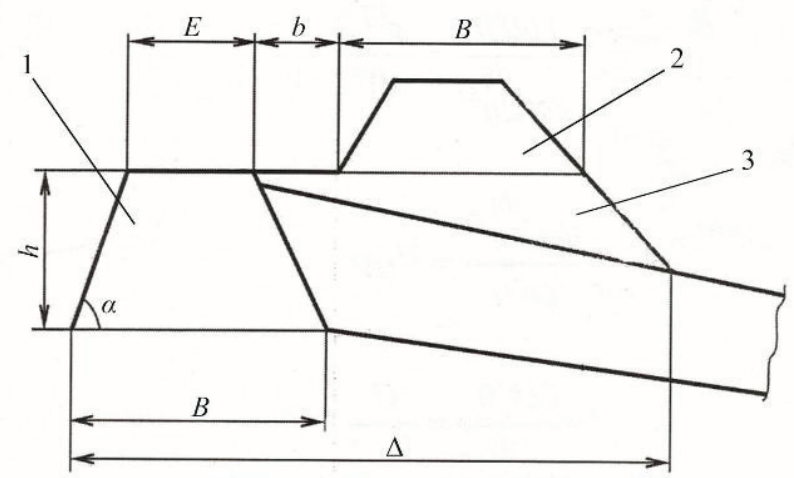

Fig. 6. The scheme for calculation of change of retaining dam parameters when transiting to the next hydraulicking layer: 1 - retaining dam of the previous hydraulicking layer; 2 - retaining dam of the current hydraulicking layer; 3 - addition of material under retaining dam.

Table 3. Intervals of change of coefficient of change of total length of the dusting surface for different variants of transition zone formation.

\begin{tabular}{|c|c|}
\hline Variant & Interval of change of $p$ value \\
\hline I & $1.1 \leq p \leq 2.0$ \\
\hline II & $0.9 \leq p \leq 1.1$ \\
\hline III & $0.1 \leq p \leq 0.9$ \\
\hline
\end{tabular}

Taking into account (1) it is possible to determine total length of the dusting surface on the current hydraulicking layer 


$$
L_{\mathrm{G}}^{(m)}=L_{\Sigma}-\Delta m
$$

where $L^{(\mathrm{m})}{ }_{\mathrm{G}}$ - total length of the dusting surface on the current hydraulicking layer, m; $L_{\Sigma}$ - total length of the dusting surface equal to the sum of lengths of the dusting surface and underwater slope, $\mathrm{m} ; m$ - number of the hydraulicking layer $(m=1$ - retaining prism).

The boundary of anthropogenic placer development depending on current layer number will be calculated beginning from the inner border of top of retaining dam berm of the first layer using following formula:

$$
L_{R}=L_{\Sigma}+(1-p) h(\eta(1+e)+\operatorname{ctg} \alpha) m .
$$

As is clear from Table 2 the boundary of anthropogenic placer separates retaining prism formed by dusting surfaces with above-water hydraulicking of sufficiently coarse solid particles from the TS core where very fine solid particles fall out in practically motionless water. Some transition zone is forming in process where underwater hydraulicking of coarse and fine particles occurs. If location of anthropogenic placer boundary must be taken into account when extracting the valuable component from retaining prism body, then location of the second transition zone boundary separating it from the core must be taken into account when estimating storage capacity.

Determination of the boundary between transition zone and TS core is not very hard in the cases of the I and the II formation variants if volume of storing cleaning rejects at the current layer and inner friction angle of storing particles in water are known. Dependences of inclination of slopes on hydraulicking layer number are linear in these cases. At the same time this dependence is essentially nonlinear when the III formation variant is realized $[1,4,5]$ :

$$
\begin{aligned}
& \Lambda=(1+B)^{2 / 3}-1 ; \\
& \Lambda=2.44 \frac{a L}{b_{0}} ; \quad B=2.61 \frac{a}{b_{0}} \frac{V_{0} h}{w \sin \alpha},
\end{aligned}
$$

where $\Lambda$ - dimensionless length of underwater slope at the first hydraulicking layer; $L$ - slope length, m; $a$ - an experimental constant from G. Abramovich's theory of planeparallel streams; $b_{0}$ is stream half-width in the initial section, $\mathrm{m} ; V_{0}$ is pulp flow velocity in the initial section, $\mathrm{m} / \mathrm{s} ; w$ is average velocity of sedimentation of particles, $\mathrm{m} / \mathrm{s}$.

Taking into account formula (4), slope dimensionless length at each new hydraulicking layer will be calculated according to dependence (Fig. 7)

$$
\begin{gathered}
\Lambda^{(m)}=\Lambda+\delta \Lambda ; \\
\delta \Lambda=q B^{z} ; \quad q=0.276 m^{1.11} ; \quad z=\frac{0.721}{m^{0.021}}
\end{gathered}
$$

where $\Lambda^{(\mathrm{m})}$ - dimensionless length of underwater slope at the hydraulicking layer with number $m ; \delta \Lambda$ - dimensionless increase of underwater slope length when transiting to the new layer (Fig. 7); $q, z-$ approximation parameters.

The relationship of $\delta \Lambda$ to $\Lambda$ (Fig. 8) is more demonstrative for illustration of movement of transition zone boundary, separating it from the core, when hydraulicking layer changes. Dependence of this relationship on layer number may be approximated with engineering accuracy by following power function if $B>7$ : 


$$
\frac{\delta \Lambda}{\Lambda}=0.292 m^{1.11}
$$

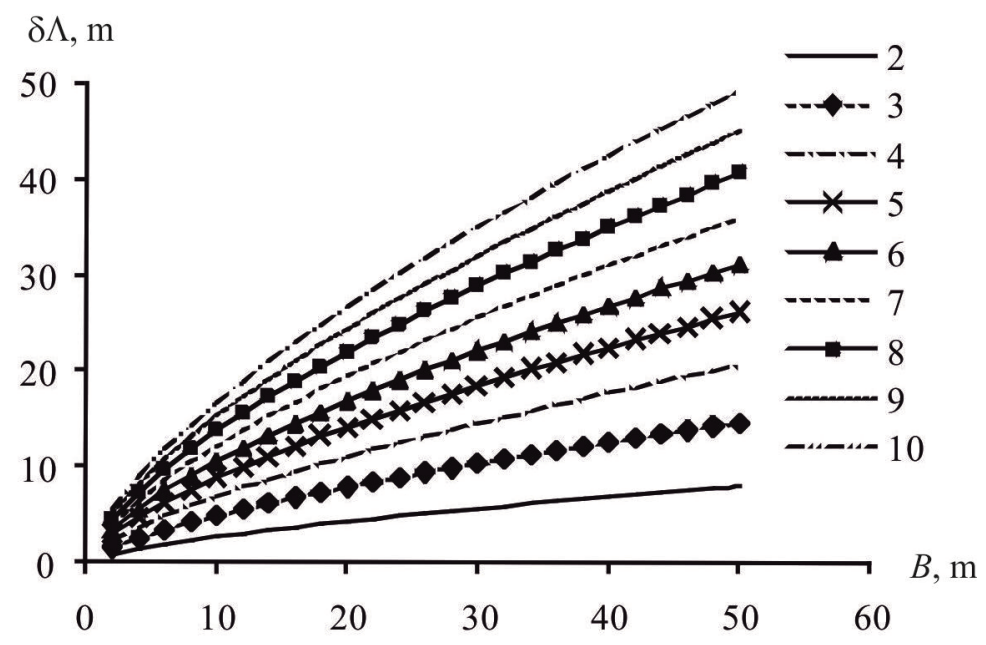

Fig. 7. Dependence of $\delta \Lambda$ on $B$ value for different numbers of the hydraulicking layer: number of the hydraulicking layer $-2,3,4,5,6, \ldots, 10$.

Figure 8 shows that length of underwater slope increases from layer to layer. This results in essential movement of transition zone boundary deep into TS core where solid particles formed underwater slope are mixing with clay, cretaceous and pulverescent particles settling in the core. This lowers prospect of extraction of valuable components from TS transition zone because recurrent concentration and separation are required.

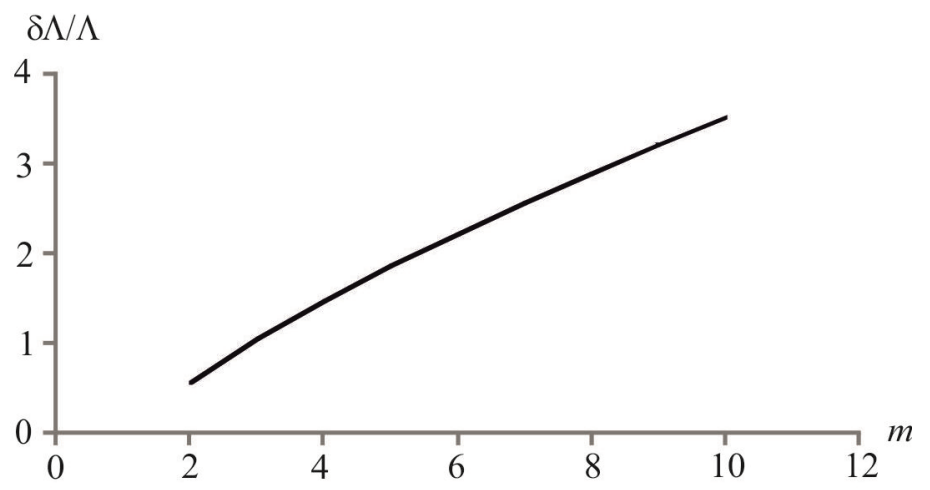

Fig. 8. Dependence of $\delta \Lambda / \Lambda$ on numder of the hydraulicking layer when $B>7$.

\section{Conclusions}

1. Possible variants of formation of boundary layer between tailings storage core and retaining prism are offered.

2. The intervals of change of coefficient of dusting surface length are determined for different variants of transition zone formation.

3. The dependences of dusting surface length and slope inclination on hydraulicking 
layer number are obtained for determination of location of the boundary between transition zone and tailings storage core. These dependences allow estimation of probable volumes of stored mineral processing products and available storage volume when building up dams. It is necessary for determination of mining parameters and for justification of technology of development of anthropogenic deposits formed in tailings storages.

\section{References}

1. Medvedeva, O.A. (2012). The analysis and state-of-the-art storage of mineral processing products. Zbagachennya korisnih kopalin, 51 (92), 22 - 29

2. Medvedeva, O. (2015). Development and exploitation of storages of enrichment process wastes as anthropogenic deposits. Theoretical and practical solutions of mineral resources mining, $567-573$

3. Semenenko, Ye.V. (2011). Nauchnyie osnovy i tehnologiy gidromehanizatsii otkryitoy razrabotki titan-tsirkonovyih rossyipey. Kiev: Naukova dumka

4. Baranov, Yu.D., Shuryigin, V.D., Blyuss, B.A., Semenenko, Ye.V. (2006). Selection and justification of the parameters of the circulating water supply system of Volnogorsky MMC. Metallurgicheskaya $i$ gornorudnaya promyishlennost [Metallurgical mining industry], 4, $100-103$

5. Smirnov, A.Ya., Evtehov, V.D., Evtehov, E.V. (2014). Geological structure of hematite quartzite deposits in the Krivoy Rog basin. Naukoviy visnik $N G U$ [Scientific Bulletin of the NMU], 2, $17-23$

6. Bespoyasko, E.A., Evtehov, V.D., Evtehov, E.V. (2013). Mineral resources base of mining and processing enterprises of the Krivoy Rog basin. Mineralogichniy zhurnal, 4, $66-71$

7. Semenenko, E., Kirichko, S. (2015). Grounds of parameters of high concentrated pulps storage technologies. Theoretical and practical solutions of mineral resources mining, $373-377$

8. Semenenko, E., Nykyforova, N., Tatarko, L. (2014). The method of hydraulic gradient and critical velocity calculation for hydrotransportation of particles with substantially different densities. In: $15^{\text {th }}$ International Freight Pipeline Society Symposium, $248-256$

9. Kubekova, S.N., Kapralova, V.I., Ibraimova, G.T., Batyrbaeva, A.A. (2016). Enrichment wastes' processing of manganiferous ores with the use of mechanochemical methods. International journal of environmental and science education. 11, 11

10. Mohamed Ibragim Mohamed Ibragim, Nanis Abd El Monem Mohamed. (2016). Towards sustainable management of solid waste in Egipt. Proceidia Environmental Science, 34, 336 - 347. doi: 10.1016/j.proenv.2016.04.030

11. Pivnyak, G., Samusia, V., Oksen, Y., Radiuk, M. (2014). Parameters optimization of heat pump units in mining enterprises. Progressive technologies of coal, coalbed methane and ores mining, 19-24.

12. Pivnyak, G., Samusia, V., Oksen, Y., Radiuk, M. (2015). Efficiency increase of heat pump technology for waste heat recovery in coal mines. New Developments in Mining Engineering 2015: Theoretical and Practical Solutions of Mineral Resources Mining, 1-4 